\title{
MICROBIAL CHARACTERIZATION OF WATER AND BIOFILMS IN DRINKING WATER DISTRIBUTION SYSTEMS AT SPORT FACILITIES
}

\author{
Lucia Bonadonna, Rossella Briancesco, Simonetta Della Libera, Ines Lacchetti, Rosa Paradiso, Maurizio Semproni \\ Department of Environment and Primary Prevention, Istituto Superiore di Sanità, Roma, Italy
}

\begin{abstract}
SUMMARY
The present study investigated the in situ microbial indicators' occurrence in water and biofilm in drinking water distribution systems of sport facilities such as gyms. The presence of Legionella, such as a potential pathogen, was also verified. Water and biofilm were contemporaneously collected and microbiologically analyzed. Few colonies of coliforms were detected in biofilm but not in the corresponding water samples. Conversely, some colonies of heterotrophs were counted at $22{ }^{\circ} \mathrm{C}$ in both the $80 \%$ biofilm samples and the $53 \%$ water samples. Legionella was detected in $29 \%$ of the hot water systems, and, in particular, L. pneumophila in $21 \%$ and $L$. non pneumophila in $9 \%$ of the samples. Higher counts were found in biofilm samples.
\end{abstract}

As it was recommended for swimming pools, it is to be hoped that hygiene risk assessment criteria and safety plans could be also developed for gyms to reduce potential hazards to health for all attendants.

Key words: biofilm, drinking water, gyms, microorganisms, plumbing system, sport facilities

Address for correspondence: L. Bonadonna, Istituto Superiore di Sanità, Viale Regina Elena, 29900161 Roma, Italy.

E-mail: lucybond@iss.it

\section{INTRODUCTION}

The main challenge for drinking water producers is the preservation of drinking water quality in distribution systems.

The European Union Drinking Water Directive 98/83/EC (1) sets out the basic parameters that every water system should strive to achieve in order to provide the cleanest, safest and most reliable drinking water possible. Even if routine monitoring is an essential component of water supply management, it is not enough to protect public health. In fact, it is well known that in all distribution systems the interior pipe walls, storage tanks, sediments, and all the surfaces in contact with finished water are colonized by microorganisms, which can survive, grow, and detach depending on local conditions. Release of microorganisms from surfaces of distribution systems into the bulk water may be one of the causes of microbial contamination, resulting in the deterioration of hygienic quality of drinking water $(2,3)$. These microenvironments create biofilm that can accumulate microorganisms, segregating and protecting them from the effects of disinfection. They are dynamic in nature, and portions are frequently sloughed off pipe surfaces; as a result, the suspended bacterial counts observed in distribution systems can be often the result of biofilm cell detachment rather than growth of organisms in the water (4-6).

Autotrophic and heterotrophic organisms, bacterial indicators, strict and opportunistic pathogens can colonize biofilms and, after mobilisation into the bulk water phase, can reach consumers. Among the opportunistic bacteria, Legionella within man-made water systems presents a potential health concern, particularly for immuno-compromised individuals. In fact, the design of centralized hot and cold water systems creates conditions that suit the growth of these bacteria $(7,8)$.

In the most recent years the number of people practising a regular physical activity has greatly increased. As a result, a greater attention is being focussed on hygienic risks associated with use of sport facilities $(9,10)$ where, healthy and immuno-competent people, as well elders, young children and people following rehabilitative treatments, exercise or swim. To obtain advantages from the physical activity and to prevent adverse effects, sports must be practised in suitable structures under the guide of qualified coachers. Nevertheless in these places, in addition of physical accidents, which represent the most frequent type of injury in sports facilities, health risks can be also linked to the use of hygienic facilities (e.g., bathrooms, showers, sinks). Control and maintenance of water distribution systems is therefore becoming a crucial task in ensuring the high quality of distributed water.

Some studies have been performed on real distribution systems investigating both water and biofilm microbial ecology; however none dealt with water distribution systems in sport facilities, such as gyms. Nevertheless, as in case of swimming pools, adverse health consequences associated with the use of these sport facilities can be prevented through a correct information on potential risks, safe behaviours and an effective and overall management.

With the aim to detect microbiological potential risks in sport facilities such as gyms, a study was carried out in some gyms to investigate both the in situ microbial indicators' occurrence and the presence of Legionella in water and biofilm in drinking water distribution systems of the hygienic facilities. 


\section{MATERIALS AND METHODS}

Sampling of water and biofilm. A total of 15 hot water samples and 19 biofilm samples were contemporaneously collected at different drinking water distribution systems in 15 gyms. A three-liter sample of tap water, standing in plumbing pipes overnight, was collected without flushing the shower heads. Samples were taken in sterile bottles containing $10 \%$ sodium thiosulphate. After the removal of the shower head, biofilms were collected by scraping the internal surface of the pipe by vigorously rubbing the surface with sterile swabs soaked in sterile distilled water. Swab samples were then kept wet in few millilitres of water collected from the same shower heads.

All the samples were transported under refrigerated conditions into the laboratory and analysed within the same day of sampling.

Microbiological analysis. Water and biofilm were analysed for microbial indicators and Legionella. All the analyses were performed in duplicate.

At the moment of the analysis, biofilm samples were eluted from swabs vortexing them into the soaking water and suspensions were prepared according to the National Standard W 15 (11).

Bacterial indicators of water quality such as E. coli, coliforms at $37^{\circ} \mathrm{C}$, enterococci and Heterotrophic Plate Count (HPC) at $22^{\circ} \mathrm{C}$ were detected in water and biofilm according to the specific analytical reference methods (1). The isolated colonies were then subcultured and identified using the Vitek automated system (BioMérieux, France).

Isolation of Legionella species was performed by concentrating 2-l water samples using $0.2 \mu \mathrm{m}$ - pore-sized polyamide filter (Millipore, USA). Each membrane was resuspended in $10 \mathrm{ml}$ of the original sample water and vortex-mixed for $10 \mathrm{~min}$. A 5-ml portion of this suspension was placed in a $50^{\circ} \mathrm{C}$ water-bath for $30 \mathrm{~min}$ for the reduction of interfering microorganisms. Aliquots of $0.1 \mathrm{ml}$ of each sample (with and without heat-pre-treatment) were spread on duplicate plates of CYE agar (charcoal yeast extract base agar, Oxoid) with BCYE growth supplement (ACES buffer/potassium hydroxyde, L-cysteine, ferric pyrophosphate, $\alpha$-ketoglutarate) and MWY selective supplement (glycine, vancomycin, polymyxin $\mathrm{B}$, anisomycin) and incubated at $35^{\circ} \mathrm{C}$, in $2.5 \%$ $\mathrm{CO}_{2}$, for 6-14 days (12). All colonies on MWY with the typical ground glass appearance of Legionella species were subcultured onto BCYE medium and CYE medium, and incubated at $35^{\circ} \mathrm{C}$ for 2 days or more. The colonies grown on BCYE, but not grown on CYE, were re-isolated and identified on the basis of cultural (lack of growth on blood agar, fluorescence), biochemical (oxidase, catalase, hydrolysis of hippurate) and serological features, using a commercial agglutination test (Legionella Latex Test,
Oxoid, UK). The test allows a separate identification of L. pneumophila serogroup 1 and serogroups 2-14 and detection of seven Legionella (polyvalent) species (other than L. pneumophila), which have been implicated in human disease: L. longbeachae, L. bozemanii 1 and 2, L. dumoffii, L. gormanii, L. jordanis, $L$. micdadei, L. anisa.

Four randomly selected $L$. pneumophila serological-positive isolates were also analyzed with the polymerase chain reaction (PCR) assay according to Declerk and coll. (13).

DNA sequences from mip gene (macrophage infectivity potentiator) were amplified (14). Three sequences of the primers were used with the aim to take into account minimal variations, if existing, of the environmental isolates:

PT69 (5' -GCATTGGTGCCGATTTGG), PT70 (5' -GCTTTGCCATCAAATCTTTCTGAA), PT 181 (5’-GTTTTGCCATCAAATCTTTTTGAA).

The amplicon was 168 bp. A blast search of the GenBank database demonstrates a high predicted specificity. All primers were part of the Perkin-Elmer EnviroAmp ${ }^{\mathrm{TM}}$ Legionella kit. Pure DNA extract ( $5 \mu \mathrm{l})$ was tested by PCR in a $25 \mu \mathrm{l}$ reaction volume that contained 0.5 units Taq DNA polymerase (Roche Diagnostic, Meylan, France), $1.5 \mathrm{mM}$ magnesium chloride, $0.2 \mathrm{mM}$ of each deoxy-nucleotriphosphate and $0.8 \mu \mathrm{M}$ of each primer. DNA was heated for $3 \mathrm{~min}$ at $95^{\circ} \mathrm{C}$ and amplified (30 cycles at $95^{\circ} \mathrm{C}$ for $45 \mathrm{~s}, 61^{\circ} \mathrm{C}$ for $45 \mathrm{~s}$ and $72^{\circ} \mathrm{C}$ for $45 \mathrm{~s}$ ). Amplification ended after one final cycle of $72^{\circ} \mathrm{C}$ (7 min). DNA extract of Legionella pneumophila ATCC 33152 was used as positive control and DNA extract of a lab isolate strain of $E$. coli as negative control.

The PCR products were analysed by agarose gel electrophoresis using $1.5 \%$ agarose gel containing ethidium bromide together with a DNA molecular weight marker (Eppendorf, Italia). Gels were viewed on a UV transilluminator and fragment sizes were compared with the 100 bp ladder DNA.

Physical and Chemical Analyses. Water temperature and residual chlorine were determined at the sampling according to reference analytical methods (15).

\section{RESULTS}

In 4 out of 19 biofilm samples a few colonies of coliforms were detected but not in the corresponding water samples. The concentration was low in all positive samples (1-3 CFU/100 ml) The isolates were assigned to the species Enterobacter amnigenus. Enterobacter intermedium and Serratia plymuthica. Conversely, some colonies of heterotrophs were counted at $22^{\circ} \mathrm{C}$ in both the $80 \%$ biofilm samples and the $53 \%$ water samples. The HPC mean concentration in biofilm was $1,2 \times 10^{3} \mathrm{CFU} / \mathrm{ml}$ (standard devia-

Table 1. Legionella in water and biofilm samples collected in drinking water distribution systems of the gyms.

\begin{tabular}{|l|c|c|c|c|}
\hline Positive samples & $\begin{array}{c}\text { noof legionellae } \\
\text { positive samples } \\
(\%)\end{array}$ & $\begin{array}{c}\text { L. pneumophila } \\
\text { serogroup 1 } \\
(\%)\end{array}$ & $\begin{array}{c}\text { L. pneumophila } \\
\text { serogroup 2-14 } \\
(\%)\end{array}$ & $\begin{array}{c}\text { Other Legionella species } \\
(\%)\end{array}$ \\
\hline Total no. & $10 / 34(26.5)$ & $2 / 34(5.8)$ & $5 / 34(14.7)$ & $3 / 34(8.8)$ \\
\hline No. of water samples & $8 / 15(46.6)$ & $1 / 15(6.6)$ & $5 / 15(33.3)$ & $2 / 15(13.3)$ \\
\hline No. of biofilm samples & $2 / 19(10.5)$ & $1 / 19(5.2)$ & $0 / 19$ & $1 / 19(5.2)$ \\
\hline
\end{tabular}


tion $0,9 \times 10^{3}$ ), whilst in the water samples was $2 \times 10^{1} \mathrm{CFU} / \mathrm{ml}$ (standard deviation $1 \times 10^{1}$ ).

The water temperature at the outlet of the showers of the 15 sport facilities ranged from $37^{\circ} \mathrm{C}$ to $42^{\circ} \mathrm{C}$ and the residual chlorine ( \pm standard deviation) in the water was $0.08 \pm 0.06 \mathrm{mg} / \mathrm{l}$.

Legionella was detected in $29 \%$ of the hot water systems, and, in particular, L. pneumophila in $21 \%$ and $L$. non pneumophila in $9 \%$ of the samples (Table 1 ). In the water samples the mean concentration was $4 \times 10^{2} \mathrm{CFU} / \mathrm{l}$ (minimum count 6.6 CFU/l, maximum count $\left.1.6 \times 10^{3} \mathrm{CFU} / \mathrm{l}\right)$, whilst a higher level of Legionella colonization was found in the biofilm where the mean count was $4 \times 10^{2} \mathrm{CFU} / \mathrm{ml}$, with the lowest and the highest concentration equal to $0.6 \mathrm{CFU} / \mathrm{ml}$ and $7.5 \times 10^{2} \mathrm{CFU} / \mathrm{ml}$, respectively. L. pneumophila serogroup 2-14 was never detected in biofilm samples but was more frequently isolated in the water samples compared to $L$. pneumophila serogroup 1 which was isolated both in water and in biofilm samples, but from two different hot water systems. In fact, the water collected from the shower heads which produced Legionella-positive biofilms was negative for the presence of the microorganism; thus Legionella positive water samples were never associated with the positive results in the corresponding biofilm samples.

Optimal PCR results were obtained while working in a PCR reaction with 30 cycles, an annealing temperature of $61{ }^{\circ} \mathrm{C}$, $1.5 \mathrm{mM} \mathrm{MgCl}_{2}$ and a primer concentration of $0.8 \mu \mathrm{M}$ (Fig. 1).

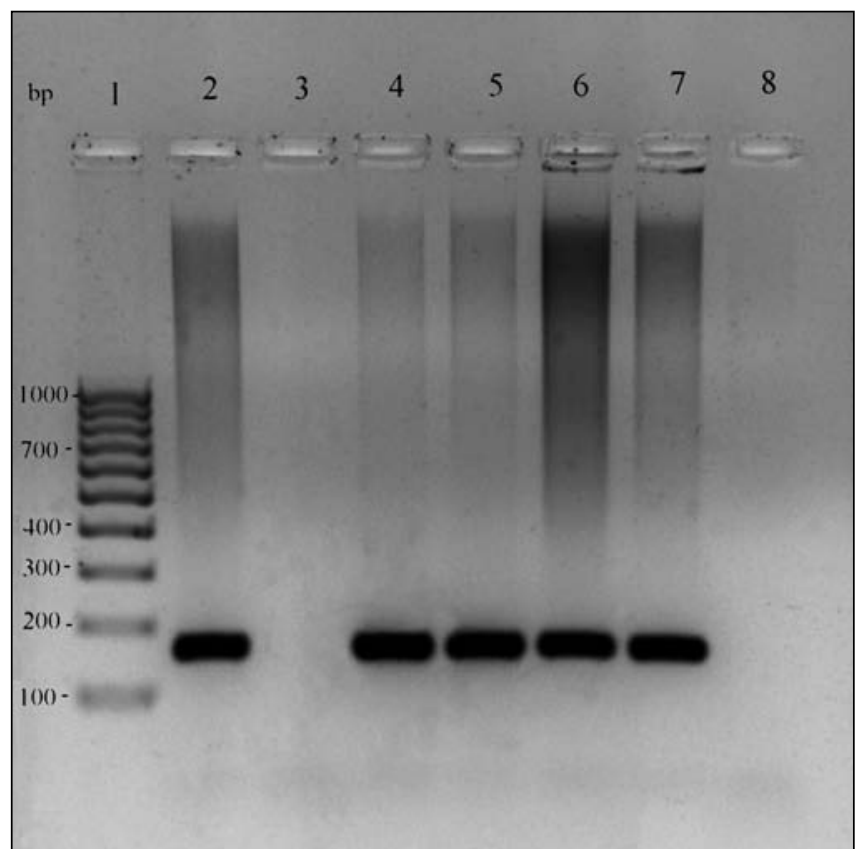

Fig. 1. Agarose gel showing amplified DNA segments from $L$. pneumophila isolated from water and biofilm with primer sets PT69; PT70; PT181.

1: standard DNA ladder; 2: positive control; 3: negative control $\left(\mathrm{H}_{2} \mathrm{O}\right)$; 4-5 amplified DNA of $L$. pneumophila isolated from water; $6-7$ : amplified DNA of $L$. pneumophila isolated from biofilm; 8: amplified DNA of $E$. coli.

\section{DISCUSSION AND CONCLUSIONS}

Drinking water in the distribution system is not sterile, regardless of the degree to which the water is treated. The water contains microbes that survive the treatment process or enter the distribution system through the pipe network. Many of these microbes can attach to the pipe wall and become part of a biofilm. Once biofilm development begins, subsequent material, organisms and contamination introduced to the distribution system can become entrained in the biofilm and may be subsequently released into the flowing water under various circumstances.

The present study showed not much correspondence in the results obtained in biofilms and water. In fact, the majority of the positive samples for biofilm (52\%) do not match with the water samples even if the water sampling, carried out without flushing, represented the worst case scenario. In fact, this sampling method allows to assess the quality of drinking water including the influence of the service network inside the building.

Coliform bacteria were detected in low concentration only in the biofilm. In fact, coliform bacteria were isolated from biofilms of 4 out of 19 showers of the gym hygienic services under consideration. Isolates belonged to environmental coliform strains that could be part of the natural water microflora. It could be suggested that low levels of coliforms below the detection limit entered the water systems and, for the observed low chlorine levels, survived in bulk water and attached to pipe materials. Some other coliform episodes have been traced to the survival and growth of coliform bacteria in distribution system biofilms $(16,17)$.

Water and biofilm analyses showed also different results for the HCP. In fact, higher microbial counts (two order of magnitude) and a higher number of positive samples (15 out of 19) were observed in biofilm samples and some pigmented colonies were recovered. Conditions such as observed in the examined distribution systems may have favoured the pigmented subpopulations. In fact, low chlorine levels, long retention times and high water temperatures are known to enhance bacterial growth (18) and increase the occurrence of pigmented bacteria (19).

Legionella is known to be a normal component of the aquatic microflora and Legionnaires' disease is recognised as a problem throughout Europe. Our study proved that Legionellae were found in water and biofilms, and different concentrations were observed in the two matrices. In fact, Legionella was recovered, on the average, with values higher than three order of magnitude in the biofilm samples. It could be expected because, for its intrinsic features, the biofilm matrix allows the organism better to survive compared to conditions prevailing in the water. An absence of association between Legionella and the traditional microbial indicators (coliforms, enterococci and E. coli) was also to be expected. In fact, it is evident the difficulty to compare the occurrence of microrganisms with different surviving likelihood, taking into account that Legionella can multiply within protozoa present in biofilm (20).

Results of amplification of mip gene carried out in this study are in accordance with other authors (21). The mip gene encodes a 24-kDa surface protein (Mip) and has been chosen as genetic marker because it plays a crucial role in the resistance of $L$. pneumophila to intracellular killing (22). The results confirmed that the specific primers well reacted with $L$. pneumophila whilst E. coli showed no reaction with each of the used primers. The four analyzed strains, recovered from water (lines $4-5$ ) and from biofilm (lines 6-7), showed the same profile. These data are in accordance with previous reports in others regions around the world, where limited genetic variability of environmental isolates 
of $L$. pneumophila in the water systems and the prevalence of one genotype of this bacterium in a large proportion of man-made aquatic environments were reported $(23,24)$.

On the ground of the obtained results, it is possible to assume that the water collected in all the distribution systems seems to have good microbial characteristics considering the bacterial indicators, whilst a potential risk could be associated with low counts of Legionella (25). Indeed a different qualitative and quantitative microbial ecology characterizes the biofilm, especially if Legionella concentrations are considered. Potable water systems containing Legionella are a significant cause of sporadic cases of legionellosis acquired in the community $(26,27)$. In the examined samples, high values of the bacterium were found in the biofilm that can play an important role in harbouring and providing favourable conditions in which the legionella bacteria may grow (28).

Facility administrators and operators should be aware of the requirements to ensure safe and enjoyable use of facilities and should be responsible for the good operation and management also of the water distribution system. Thus an adequate planning, design, installation and management of the plumbing system must be followed by fully hygienic operations and maintenance.

Hygienic controls and management interventions were recommended for sport facilities such as swimming pools by the WHO (29). Dealing with infectious disease in common people or athletes practising sport in gyms could be, perhaps, not as dramatic as attending to a sudden on-field injury. Nevertheless, even if it is recognized that the fitness produced by regular, moderate exercise improves immunity, recent studies postulated that exercise, especially during competitions, may produce a period of immunodepression, thus creating an "open window" when the athlete may be more susceptible to infection (30).

Good general hygiene practices and interventions, and efforts to minimize exposure to specific risks form the foundation of all the prevention activities. Thus, as in case of swimming pools, it is to be hoped that hygiene risk assessment criteria and safety plans could be also developed for gyms aiming at reduction of potential health hazards for all attendants.

\section{REFERENCES}

1. Council directive $98 / 83 /$ EC of 3 November 1998 on the quality of water intended for human consumption. Off J Eur Commun. 1998 Dec 5;41(330):32-54.

2. Servais P, Anzil A, Gatel D, Cavard J. Biofilm in the Parisian suburbs drinking water distribution system. J Water SRT-AQUA. 2004 Jul;53(5):313-24.

3. Wingender J, Flemming HC. Contamination potential of drinking water distribution network biofilms. Water Sci Technol. 2004;49(11-12):277-86.

4. Van der Wende E, Characklis WG, Grochowski J. Bacterial-growth in water distribution systems. Water Sci Technol. 1988;20(11-12):521-4.

5. Sharp RR, Camper AK, Crippen JJ, Schneider OD, Leggiero S. Evaluation of drinking water biostability using biofilm methods. J Environ Eng. 2001 May;127(5):403-10.

6. Choi YC, Morgenroth E. Monitoring biofilm detachment under dynamic changes in shear stress using laser-based particle size analysis and mass fractionation. Water Sci Technol. 2003;47(5):69-76.

7. Stoodley P, Wilson S, Hall-Stoodley L, Boyle JD, Lappin-Scott HM, Costerton JW. Growth and detachment of cell clusters from mature mixedspecies biofilms. Appl Environ Microbiol. 2001 Dec;67(12):5608-13.

8. Van der Kooij D, Veenendaal HR, Scheffer WJ. Biofilm formation and multiplication of Legionella in a model warm water system with pipes of copper, stainless steel and cross-linked polyethylene. Water Res. 2005 Aug;39(13):2789-98.

9. Polak W. Biogenous deposits (biofilms) in warm water circuits: their effect and control in swimming pool and shower circuits. In: Dunemann L, Höller C editors. Pool and Spa 2007: Proceedings of the 2nd International Pool and Spa Conference; 2007 Mar 13-16; Munich, Germany. Munich: Verein für Wasser-, Boden- und Lufthygiene, Bavarian Health and Food Safety Authority; 2007.

10. Schindler P, Gerber L, Höller C. Legionella in swimming pools. In: Dunemann L, Höller C, editors. Pool and Spa 2007: Proceedings of the 2nd International Pool and Spa Conference; 2007 Mar 13-16; Munich, Germany. Munich: Verein für Wasser-, Boden- und Lufthygiene, Bavarian Health and Food Safety Authority; 2007.

11. Detection and enumeration of Legionella species in biofilms and sediments. National standard method W 15. Issued by: Standards Unit, Evaluations and Standards Laboratory, in conjunction with the Regional Food, Water and Environmental Coordinators Forum. London: Health Protection Agency; 2006.

12. Leoni E, de Luca G, Legnani PP, Sacchetti R, Stampi S, Zanetti F. Legionella waterline colonization: detection of Legionella species in domestic, hotel and hospital hot water systems. J Appl Microbiol. 2005;98(2):373-9.

13. Declerck P, Verelst L, Duvivier L, van Damme A, Ollevier F. PCR as a test for the presence or absence of Legionella in (cooling) water. Water Sci Technol. 2003;47(3):103-7.

14. Wilson DA, Yen-Lieberman B, Reischl U, Gordon SM, Procop GW. Detection of Legionella pneumophila by real-time PCR for the mip gene. J Clin Microbiol. 2003 Jul;41(7):3327-30.

15. Ottaviani M, Bonadonna L, editors. Analytical methods for drinking water. Rapporti ISTISAN 97/8. Roma: Istituto Superiore di Sanità; 1997. (In Italian.)

16. LeChevallier MW, Welch NJ, Smith DB. Full-scale studies of factors related to coliform regrowth in drinking water. Appl Environ Microbiol. 1996 Jul;62(7):2201-11.

17. LeChevallier MW. Biofilms in water distribution systems: control and remediation. In: Keevil CW, Godfree A, Holt D, Dow C, editors. Biofilm in the aquatic environment. Cambridge: Royal Society of Chemistry; 1999. p. 220-30.

18. LeChevallier MW, Babcock TM, Lee RG. Examination and characterization of distribution system biofilms. Appl Environ Microbiol. 1987 Dec;53(12):2714-24.

19. Reasoner DJ, Blannon JC, Geldreich EE, Barnick J. Nonphotosynthetic pigmented bacteria in a potable water treatment and distribution system. Appl Environ Microbiol. 1989 Apr;55(4):912-21.

20. Murga R, Forster TS, Brown E, Pruckler JM, Fields BS, Donlan RM. Role of biofilms in the survival of Legionella pneumophila in a model potable-water system. Microbiology. 2001 Nov;147(Pt 11):3121-6.

21. Ratcliff RM, Lanser JA, Manning PA, Heuzenroeder MW. Sequencebased classification scheme for the genus Legionella targeting the mip gene. J Clin Microbiol. 1998 Jun;36(6):1560-7.

22. Cianciotto NP, Bangsborg JM, Eisenstein BI, Engleberg NC. Identification of mip-like genes in the genus Legionella. Infect Immun. 1990 Sep;58(9):2912-8.

23. Darelid J, Bernander S, Jacobson K, Löfgren S. The presence of a specific genotype of Legionella pneumophila serogroup 1 in a hospital and municipal water distribution system over a 12-year period. Scan J Infect Dis. 2004;36(6-7):417-23.

24. Lepeuple AS, Jovic M, de Roubin MR. Molecular typing of the Legionella pneumophila population isolated from several locations in a contaminated water network. Water Sci Technol. 2004;50(1);281-5.

25. European Working Group for Legionella Infections (EWGLI) [homepage on the Internet]. European guidelines for control and prevention of travel associated legionnaires' disease [cited 2008 July 22]. Available from: http://www.ewgli.org/data/european_guidelines.htm.

26. Mandell GL, Bennett JE, Dolin R. Legionella. Philadelphia: Churchill Livingston; 2005.

27. Scaturro M, Losardo M, de Ponte G, Ricci ML. Comparison of three molecular methods used for subtyping of Legionella pneumophila strains isolated during an epidemic of legionellosis in Rome. J Clin Microbiol. 2005 Oct;43(10):5348-50.

28. Rogers J, Dowsett AB, Dennis PJ, Lee JV, Keevil CW. Influence of temperature and plumbing material selection on biofilm formation and growth of Legionella pneumophila in a model potable water system containing complex microbial flora. Appl Environ Microbiol. 1994 May;60(5):1585-92.

29. Guidelines for safe recreational water environments. Volume 2: swimming pools and similar environments. Geneva: World Health Organization; 2006.

30. Howe WB. Preventing infectious disease in sports. Phys Sports Med. 2003;31(2):23-30. 